\title{
Hashimoto Encephalopathy as a Complication of Autoimmune Thyroiditis
}

\author{
Alixandria A. Fiore ${ }^{a}$ Wilson B. Pfeiffer ${ }^{a}$ Syed A.A. Rizvi ${ }^{b}$ Anais Cortes ${ }^{c}$ \\ Conrad Ziembinskic ${ }^{c}$ Ronald Pham ${ }^{c}$ Stephanie Graves ${ }^{c}$ Urvesh Patel $^{c}$ \\ ${ }^{a}$ Nova Southeastern University, Fort Lauderdale, FL, USA; ${ }^{b}$ Hampton University, School of Pharmacy, \\ Hampton, VA, USA; ' Palmetto General Hospital, Miami, FL, USA
}

\section{Significance of the Study}

- Hashimoto encephalopathy was diagnosed in a previously healthy 56-year-old female who presented with progressive cognitive decline and visual hallucinations. Extensive laboratory and diagnostic workup was done over the course of a 15-day hospitalization. The clinical picture of this patient illustrates the importance of awareness for Hashimoto encephalopathy, one of the few easily treatable causes of cognitive decline.

\section{Keywords}

Hashimoto encephalopathy - Autoimmune thyroiditis .

Steroid-responsive encephalopathy

\begin{abstract}
Objective: To present a case of Hashimoto encephalopathy as a complication of autoimmune thyroiditis. Clinical Presentation and Intervention: A previously healthy 56-yearold female presented with rapidly progressive cognitive decline and visual hallucinations. Being a diagnosis of exclusion, Hashimoto encephalopathy required an extensive laboratory and diagnostic workup, which was done over the course of a 15-day hospitalization. The patient recovered after initial treatment with intravenous methylprednisolone and was then switched to prednisone p.o. Conclusion: This case report illustrates the importance of awareness for Hashimoto encephalopathy, as it remains one of the few easily treatable and reversible causes of rapid cognitive decline.

(c) 2018 The Author(s)

Published by S. Karger AG, Basel
\end{abstract}

\section{Introduction}

Encephalopathy is a broad diagnosis which can be caused by many different pathologic processes [1]. When creating a differential diagnosis for a patient with altered mental status and encephalopathy, a wide net must be cast to narrow down the possible causes. Common etiologies for encephalopathy may include but are not limited to uremic, hypertensive, hepatic, metabolic, infectious, paraneoplastic, and autoimmune etiologies among others. One very rare cause of acute encephalopathy is Hashimoto encephalopathy as a complication of autoimmune thyroiditis [2]. Patients presenting with neurologic changes consistent with encephalopathy must be further classified as either acute, chronic, or acute and chronic in order to facilitate a list of differential diagnoses. A syndrome of delirium and/ or rapidly progressive dementia can help narrow the list of potential diagnoses, with Hashimoto encephalopathy being one potential cause. The diagnosis of Hashimoto encephalopathy is made as a diagnosis of exclusion, requiring the ruling out of many other potential causes [3].

\begin{tabular}{ll}
\hline KARGER & $\begin{array}{l}\text { ( 2018 The Author(s) Karger } \\
\text { Published by S. Karger AG, Basel Open cacess }\end{array}$ \\
E-Mail karger@karger.com & $\begin{array}{l}\text { This is an Open Access article licensed under the Creative Commons } \\
\text { Attribution-NonCommercial-4.0 International License (CC BY-NC) } \\
\text { (http://www.karger.com/Services/OpenAccessLicense), applicable to } \\
\text { the online version of the article only. Usage and distribution for } \\
\text { commercial purposes requires written permission. }\end{array}$
\end{tabular}


Table 1. Laboratory data of the patient

\begin{tabular}{lll}
\hline Parameters & Observed values & Reference range \\
\hline Hemoglobin & $11.7 \mathrm{~g} / \mathrm{dL}$ & $12-16 \mathrm{~g} / \mathrm{dL}$ \\
Leukocyte count & $8,600 \mathrm{cells} / \mu \mathrm{L}$ & $4,500-10,000 \mathrm{cells} / \mu \mathrm{L}$ \\
Glucose & $102 \mathrm{mmol} / \mathrm{L}$ & $70-100 \mathrm{mg} / \mathrm{dL}$ \\
Sodium & $140 \mathrm{mEq} / \mathrm{L}$ & $135-145 \mathrm{mEq} / \mathrm{L}$ \\
Potassium & $3.8 \mathrm{mEq} / \mathrm{L}$ & $3.5-5.0 \mathrm{mEq} / \mathrm{L}$ \\
Calcium & $9.5 \mathrm{mg} / \mathrm{dL}$ & $8.5-10.2 \mathrm{mg} / \mathrm{dL}$ \\
Creatinine & $1.0 \mathrm{mg} / \mathrm{dL}$ & $0.5-1.1 \mathrm{mg} / \mathrm{dL}$ \\
Chloride & $106 \mathrm{mg} / \mathrm{dL}$ & $96-106 \mathrm{mEq} / \mathrm{L}$ \\
Blood urea nitrogen & $15 \mathrm{mg} / \mathrm{dL}$ & $7-20 \mathrm{mg} / \mathrm{dL}$ \\
Total bilirubin & $0.53 \mathrm{mg} / \mathrm{dL}$ & $0.1-1.2 \mathrm{mg} / \mathrm{dL}$ \\
\hline Direct bilirubin & $0.2 \mathrm{mg} / \mathrm{dL}$ & $<0.3 \mathrm{mg} / \mathrm{dL}$ \\
Thyroid-stimulating hormone & $1.79 \mu \mathrm{U} / \mathrm{L}$ & $2.3-4.0 \mu \mathrm{U} / \mathrm{L}$ \\
Free thyroxine (T4) & $0.99 \mathrm{ng} / \mathrm{dL}$ & $1.0-2.0 \mathrm{ng} / \mathrm{dL}$ \\
Vitamin B ${ }_{12}$ level & $520 \mathrm{pg} / \mathrm{mL}$ & $200-1,100 \mathrm{pg} / \mathrm{mL}$ \\
Serum West Nile virus IgG & $n e g a t i v e$ & - \\
Serum West Nile virus IgM & negative & - \\
Urine drug screen (amphetamines, barbiturates, & negative & - \\
benzodiazapines, cocaine, opiates, phencyclidine, and & & \\
tetrahydrocannabinol) & & \\
Ethanol level & $<10.0 \mathrm{mg} / \mathrm{dL}$ & $<10.0 \mathrm{mg} / \mathrm{dL}$ \\
\hline
\end{tabular}

\section{Case Report}

A 56-year-old female was brought to the emergency department with rapidly progressive cognitive decline and visual hallucinations over the course of the previous 3 weeks. Her past medical history was pertinent only for anxiety, migraines, and gastroesophageal reflux disease. The patient's family history included multiple cerebral vascular accidents, epilepsy, thyroid disease, non-insulin dependent type 2 diabetes mellitus, and colon cancer. Her past surgical history included liposuction, bilateral gluteal fat implants, abdominoplasty, and bilateral breast reduction/breast lift. The patient had never before experienced any episodes of cognitive decline or hallucinations. On physical exam, the patient appeared drowsy and lethargic but was able to be aroused with pain stimulus and loud noise. She was unable to follow most commands, with the opening of mouth and sticking out of tongue being the only commands that were followed. The patient was not oriented to person, place, or time. Examination of the abdomen, chest, and extremities was not possible due to the patient's unresponsiveness. Heart auscultation revealed regular rate and rhythm with S1 and S2 present. The lungs were clear to auscultation bilaterally in both upper and lower airways. Laboratory workup included: Hgb $11.7 \mathrm{~g} / \mathrm{dL}, \mathrm{HCT} 35.1 \mathrm{~g} / \mathrm{dL}$, glucose $102 \mathrm{mmol} / \mathrm{L}$, sodium $140 \mathrm{mmol} / \mathrm{L}$, potassium $3.8 \mathrm{mmol} / \mathrm{L}$, calcium $9.5 \mathrm{mg} / \mathrm{dL}$, creatinine $1.0 \mathrm{mg} / \mathrm{dL}$, chloride $106 \mathrm{mg} / \mathrm{dL}, \mathrm{BUN}$ $15 \mathrm{mg} / \mathrm{dL}$, bilirubin total $0.53 \mathrm{mg} / \mathrm{dL}$, bilirubin direct $0.2 \mathrm{mg} / \mathrm{dL}$, TSH $1.79 \mu \mathrm{IU} / \mathrm{L}$ (range: $0.450-4.500$ ), free T4 $0.99 \mathrm{ng} / \mathrm{dL}$ (range: $0.8-1.8$ ), and vitamin $B_{12} 520 \mathrm{pg} / \mathrm{mL}$ (range: $200-1,100$ ). Ethanol $<10.0 \mathrm{mg} / \mathrm{dL}$, amphetamines, barbiturates, benzodiazepines, cocaine, opiates, phencyclidine, and tetrahydrocannabinol were all negative.
Upon arrival at the emergency department, the patient was taken for a CT-STAT of the head and brain which showed no verifiable acute intracranial abnormalities. Then, she underwent a chest $\mathrm{X}$-ray which showed no radiographic evidence of acute cardiopulmonary disease. CBC, BMP, urinalysis, and urine drug screen were then ordered which showed no acute abnormalities (Table 1). The neurology and psychiatry departments were consulted, and the patient was admitted to the step-down unit. Due to the acuity of the presenting symptoms, the patient was examined for subacute encephalopathy versus rapidly progressive encephalopathy. MRI of the brain (without contrast), standard EEG, thyroid antibody panel, vitamin $B_{12}$ level, and rapid plasma reagin (RPR) were all ordered on day 2 of hospitalization.

On day 3, the patient reported visual hallucinations and was oriented to person and time but not place. She was immediately started on levetiracetam, Haldol, and lorazepam for acute psychosis. Standard EEG results on day 3 showed bilateral temporal neuronal dysfunction (left $>$ right) with the absence of seizure-like activity. Due to the epileptogenic potential of the standard EEG findings, a 24-hour EEG was then ordered to assess for epilepsy. On day 4, the patient remained oriented to person and time but not place with significant agitation. The results of the MRI of the brain (without contrast) showed several lesions within the supratentorial white matter, which were bright on DWI sequences with an area of cortical enhancement in the right occipital lobe and a periventricular lesion extending into the corpus callosum. This was of concern due to infarcts of a possible embolic etiology which prompted a cardiology consult.

On day 5 , the patient remained oriented to person and time but not place with significant agitation. Lumbar puncture results (Table 2) showed no oligoclonal bands (ruling out multiple sclerosis),
Fiore/Pfeiffer/Rizvi/Cortes/Ziembinski/ Pham/Graves/Patel 
Table 2. CSF analysis

\begin{tabular}{lll}
\hline Parameters & Observed values & Reference range \\
\hline Oligoclonal bands & none seen & - \\
IgG antibody level & $9.9 \mathrm{mg} / \mathrm{dL}$ & $0.0-8.1 \mathrm{mg} / \mathrm{dL}$ \\
Protein level & $126 \mathrm{mg} / \mathrm{dL}$ & $15-45 \mathrm{mg} / \mathrm{dL}$ \\
Antithyroglobulin antibody & $121.1 \mathrm{IU} / \mathrm{mL}$ & $<20 \mathrm{IU} / \mathrm{mL}$ \\
Antithyroid peroxidase & $175 \mathrm{IU} / \mathrm{mL}$ & $<35 \mathrm{IU} / \mathrm{mL}$ \\
Anti-treponemal antibody & positive & - \\
RPR & negative & - \\
West Nile virus IgG & negative & - \\
West Nile virus IgM & negative & - \\
VDRL test & non-reactive & - \\
Toxoplasma antibody & negative & - \\
Acid-fast bacilli & negative & - \\
CSF culture & no growth & - \\
CSF pathology & no malignant cells seen & - \\
CSF flow cytometry & negative & \\
\hline
\end{tabular}

Table 3. Autoimmune panel

\begin{tabular}{lll}
\hline Parameters & Observed values & Reference range \\
\hline C3 & $119 \mathrm{mg} / \mathrm{dL}$ & $88-206 \mathrm{mg} / \mathrm{dL}$ \\
C4 & $26.5 \mathrm{mg} / \mathrm{dL}$ & $13-75 \mathrm{mg} / \mathrm{dL}$ \\
Angiotensin-converting enzyme level & $36 \mathrm{U} / \mathrm{L}$ & $8-53 \mathrm{U} / \mathrm{L}$ \\
Anti-double stranded DNA & negative & $<30.0 \mathrm{IU} / \mathrm{mL}$ \\
Rheumatoid factor level & negative & $<20.0 \mathrm{U}$ \\
Perinuclear antineutrophil cytoplasmic antibodies & $<1.2$ titer & - \\
Cytoplasmic antineutrophil cytoplasmic antibodies & $<1.2$ titer & - \\
Anti-Sjögren's syndrome-related antigen A level & $<0.20 \mathrm{U}$ & $<1.0 \mathrm{U}$ \\
Anti-Sjögren's syndrome-related antigen B level & $<0.20 \mathrm{U}$ & $<1.0 \mathrm{U}$ \\
\hline
\end{tabular}

${ }^{a}$ Angiotensin-converting enzyme gene polymorphism.

IgG $9.9 \mathrm{mg} / \mathrm{dL}$ (normal 0.0-8.1), protein $126 \mathrm{mg} / \mathrm{dL}$ (normal 1545 ), positive anti-treponemal $\mathrm{Ab}$, negative RPR, and negative West Nile virus IgG and IgM. Serum West Nile virus IgG and IgM were also negative. Thyroid peroxidase $\mathrm{Ab}(\mathrm{TPO} \mathrm{Ab})$ and thyroglobulin Ab showed TPO Ab $175 \mathrm{IU} / \mathrm{mL}$ (normal <35) and thyroglobulin $\mathrm{Ab} 121.1 \mathrm{IU} / \mathrm{mL}$ (normal $<20$ ). Due to the combination of cerebral spinal fluid (CSF) changes and thyroid antibody panel results, intravenous methylprednisolone $1,000 \mathrm{mg} /$ day was started. Venereal Disease Research Laboratory test (VDRL) was also ordered to rule out possible neurosyphilis.

On day 6 , the patient remained oriented to person and time but not place with significant agitation. Autoimmune workup was initiated and C3, C4, ACE, ANA, dsDNA, RF, atypical pANCA, CANCA, anti-SSA, and anti-SSB levels were all negative (Table 3 ). CTs of the chest, abdomen, and pelvis were obtained to rule out paraneoplastic etiology. The results of all CT scans were negative for neoplastic changes. An ultrasound of the bilateral carotid arteries was performed, which showed no stenosis. Intravenous methylprednisolone $1,000 \mathrm{mg} /$ day was continued. On day 7 , the patient remained oriented to person and time but not place with significant agitation. PCR of the serum definitively ruled out HSV-1 and -2 as a cause of encephalopathy (HSV encephalitis). Intravenous methylprednisolone $1,000 \mathrm{mg}$ /day was continued.

On day 8 , the patient remained oriented to person and time but not place. Her agitation had decreased. Due to underlying microcytic anemia and a remaining lack of definitive diagnosis, the patient was taken for colonoscopy to rule out a gastrointestinal lesion that could account for the anemia, as well as to rule out a potential gastrointestinal metastatic cause of the continued altered mental status. Colonoscopy showed a 3-mm tubular adenoma, which was removed; it was negative for malignancy. Transesophageal echocardiogram on day 8 showed ejection fraction $>60 \%$, the absence of wall motion abnormalities, and the absence of valvular disease. These results ruled out a cardioembolic cause of encephalopathy. Intravenous methylprednisolone $1,000 \mathrm{mg}$ /day was continued through days 8 to 10 . On days 9 and 10, the patient remained oriented to person and time but not place with continued lessening of her agitation. The patient was also becoming visibly more active. 
On day 11, the patient was able to respond well to both voice and commands and was oriented to person, time, and place. MRA of the brain was obtained which was unremarkable, ruling out further vascular etiologies of altered mental status. At this time, the patient was transitioned from intravenous methylprednisolone $1,000 \mathrm{mg} /$ day to prednisone $60 \mathrm{mg}$ /day p.o. On day 12, the patient was oriented to person, time, and place and was very responsive. There was no agitation. CSF culture results and CSF acid-fast bacilli results were negative. CSF pathology was also negative for malignant cells. On days 13 and 14, the patient remained oriented to person, time, and place and began ambulating with the help of the physical therapy team. CSF flow cytometry results were obtained on day 14 which was negative for lymphoproliferative processes. The patient remained on prednisone $60 \mathrm{mg}$ /day p.o.

On day 15 , the patient continued to improve. She was oriented to person, time and place, was awake and responsive and was able to ambulate on her own. After receiving negative results for both CSF VDRL and toxoplasma Ab IgM, the diagnosis of steroid-responsive encephalopathy (Hashimoto encephalopathy) as a complication of Hashimoto's thyroiditis was made. The patient was discharged with prednisone $60 \mathrm{mg} /$ day p.o. with outpatient followup scheduled within 1 week in the clinic.

\section{Discussion}

First described in 1966 by Brain et al., Hashimoto encephalopathy is a disease with no specific known cause and can occur even with normal thyroid function despite the presence of antithyroid antibodies. Once a potential diagnosis of Hashimoto encephalopathy is considered, conditions that must be ruled out include CreutzfeldtJakob disease, acute disseminated encephalomyelitis, toxic metabolic encephalopathies, meningoencephalitis, psychiatric disease, carcinomatous meningitis, paraneoplastic encephalitis, frontotemporal dementia, stroke/ TIA, cerebrovasculitis, and basilar or hemiplegic migraine. Once all other etiologies are definitively ruled out, a diagnosis of Hashimoto encephalopathy can be considered [4].

In addition to ruling out all other etiologies, there are 3 essential features that must be present in order to diagnose Hashimoto encephalopathy: altered consciousness with reduced wakefulness, attention, or cognitive function, no CSF evidence of bacterial or viral infection; and high serum concentration (or titer) of antithyroid microsomal, antithyroid peroxidase, or antithyroglobulin antibodies [5]. To further support a diagnosis of Hashimoto encephalopathy, it is also essential that the patient has a profound improvement of mental status upon administration of a steroid treatment regimen. Because of this, Hashimoto encephalopathy has also been termed steroidresponsive encephalopathy [6]. Hashimoto encephalopa- thy has an estimated prevalence of 2.1 per 100,000 patients with unexplained neurologic symptoms, with a median age at onset of 56 years and women being more affected than men [5]. In 2003, a 35-year national retrospective study showed that out of all patients in the United States who presented with noninfectious encephalopathy and a high serum antithyroid antibody concentration, only 105 patients were diagnosed with Hashimoto encephalopathy [7]. A total of $50 \%$ of patients presents with focal or diffuse nonenhancing MRI abnormalities during subacute exacerbation, and it can also be associated with nonspecific EEG abnormalities and elevated CSF proteins $[8,9]$.

Given the rarity of the condition, the exact dosage of steroids has not yet been established and there is no specific, accepted standard of care for the condition at this time. Daily oral prednisone $(50-150 \mathrm{mg}$ ) as well as daily high-dose intravenous methylprednisolone have both been used, with the benefit of intravenous as compared to oral steroids being unknown. A total of $90-98 \%$ of patients with Hashimoto encephalopathy who are treated with steroids respond within weeks to months, with full recovery often achieved [10].

\section{Conclusion}

This case shows the importance of keeping a broad list of differential diagnoses to clinical practitioners when dealing with an encephalopathic patient, especially in the presence of antithyroid antibodies. It is essential for physicians to test for antithyroid antibodies in every case of acute encephalopathy as a means of ruling out or further exploring a diagnosis of Hashimoto encephalopathy. While it remains an extremely rare cause, it is also one of the few treatable and easily reversible causes of acute encephalopathy, making it much more important for the physician to recognize and treat.

\section{Statement of Ethics}

The authors have no ethical conflicts to disclose.

\section{Disclosure Statement}

The authors have no conflicts of interest to disclose.
Med Princ Pract 2019;28:91-95 DOI: $10.1159 / 000494800$
Fiore/Pfeiffer/Rizvi/Cortes/Ziembinski/ Pham/Graves/Patel 


\section{References}

1 Oehmichen M, Auer RN, Ha König HG. Forensic Neuropathology and Associated Neurology. Berlin (DE): Springer Science \& Business Media; 2006

2 Chong JY, Rowland LP, Utiger RD. Hashimoto encephalopathy: syndrome or myth? Arch Neurol. 2003 Feb;60(2):164-71.

3 Graus F, Titulaer MJ, Balu R, Benseler S, Bien CG, Cellucci T, et al. A clinical approach to diagnosis of autoimmune encephalitis. Lancet Neurol. 2016 Apr;15(4):391-404.

4 Carbone A, Amenduni T, Bruno R. Hashimoto's encephalopathy (HE): an under diagnosed autoimmune-mediated encephalopathy. Endocrine. 2016 Nov;54(2):572-3.
5 Philip R, Saran S, Gutch M, Gupta K. An unusual presentation of Hashimoto's encephalopathy. Indian J Endocrinol Metab. 2014 Jan; 18(1):113-5.

6 Castillo P, Woodruff B, Caselli R, Vernino S, Lucchinetti C, Swanson J, et al. Steroid-responsive encephalopathy associated with autoimmune thyroiditis. Arch Neurol. 2006 Feb;63(2):197-202.

7 Brain L, Jellinek EH, Ball K. Hashimoto's disease and encephalopathy. Lancet. 1966 Sep; 2(7462):512-4.
8 Grommes C, Griffin C, Downes KA, Lerner AJ. Steroid-responsive encephalopathy associated with autoimmune thyroiditis presenting with diffusion $\mathrm{MR}$ imaging changes. AJNR Am J Neuroradiol. 2008 Sep;29(8): $1550-1$.

9 Anand KS, Garg J, Verma R, Chakraborty A. Hashimoto's Encephalitis: Unusual Cause of Reversible Dementia. J Family Med Prim Care. 2014 Jul;3(3):284-6.

10 Jacob S, Rajabally YA. Hashimoto's encephalopathy: steroid resistance and response to intravenous immunoglobulins. J Neurol Neurosurg Psychiatry. 2005 Mar;76(3):455-6. 